\title{
Conceptual analysis of Eco-efficiency and Industrial Symbiosis: insights from process industry
}

\author{
Yan $\mathrm{Li}^{*}$, Maria Holgado, Miriam Benedetti, Steve Evans \\ Institute for Manufacturing. University of Cambridge \\ 17 Charles Babbage Road, CB3 OFS Cambridge, UK \\ $\left\{{ }^{*} \mathrm{yl} 483, \mathrm{mh} 769, \mathrm{mb} 2132, \mathrm{se} 321\right\} @$ cam.ac.uk
}

\begin{abstract}
The interior relationship between Industrial Ecology, Eco-Efficiency and Industrial Symbiosis has been scarcely investigated in literature. We identify three main aspects linking the concepts, which are 'Actions', 'Stakeholders' and 'Value', and use them to drive the conceptual analysis. Considering the application and implementation, authors conduct a conceptual comparison between Eco-Efficiency and Industrial Symbiosis by using Industrial Ecology as the leading concept. A conceptual framework is developed to uncover the relationship of Industrial Ecology, Eco-Efficiency and Industrial Symbiosis, from a firm level perspective.
\end{abstract}

Keywords: Industrial Ecology; Industrial Symbiosis; Eco-Efficiency; sustainable value; process industry; energy efficiency; resource efficiency; firm analysis

\section{Introduction}

Innovations oriented to sustainability pursue real and substantial improvements by developing superior production processes, products and services and by exercising large market influence as well as social or political influence [1]. Industrial Ecology (IE) is a leading concept for sustainability-oriented innovations. It is strongly connected to the idea of closing material loops, thus, emphasizing on materials and energy flows and life cycle perspectives at firm, inter-firm and regional/global levels [2]. IE related innovations drive increasing attention to the development of ecologically benign, clean resources, technologies and new products [3]. Still a relatively new field, IE is "a cluster of concepts, tools, metaphors and exemplary applications and objectives" [2]. Among the myriad of concepts within the IE frameworks, Eco-Efficiency (EE) and Industrial Symbiosis (IS) are highlighted as firm level and inter-firm level guiding concepts $[4,5]$. Whereas they are considered as key parts of IE, there is no current research effectively explaining the interior relationship of these concepts (EE, IS, IE) in one context. Some authors have connected IS and EE through the use of EE indicators to assess the impact of the application of IS $[6,7]$. This research aims at investigating the connections between EE and IS under the frame of IE as guiding concept.

The research focuses on the process industry in order to provide a context for our exploratory reasoning at conceptual level and as a key industry with strong impact on sustainability at European and global level. Nine industry sectors are considered as part of the process industry [8]: chemicals, food, glass, paper and pulp, pharmaceuticals, metal, rubber and plastics, textile and building materials. The process industry is often characterized as energy-intensive and resource-intensive, with a significant contribution to GHG emissions and a high dependence on resources availability [9]. This makes it especially a good target for implementation of new strategies and methods for increasing resource and energy efficiency. The potential gains of implementing IE oriented innovations would have a huge impact on environmental and societal aspects.

Authors define our research question as follows: How firms in process industry can implement better EE and IS concepts? There are three steps defined to answer this research question. Initially, an analysis at conceptual level of EE and IS has been performed and this provided an initial conceptual framework for our research. A second step looks at in-company analysis to understand the necessary capabilities for EE and IS implementation and possible synergies 
between them. Finally, our research aims at developing tools and methods to support companies in their EE and IS implementation activities. This paper presents our results regarding the first research step. An extensive literature review has been performed to develop the initial conceptual framework; besides, case studies from secondary data sources are analyzed to illustrate the potential effectiveness of the conceptual framework.

\section{Background}

\subsection{Eco-Efficiency}

In the 1970s, EE was first suggested as a concept of environmental efficiency. In the 1990s, environmental factors compelled a new interest in manufacturing sectors. At this stage, the role of industry has changed from being the cause of environmental degradation to a driver for sustainability. Therefore, as a business links to sustainable development, the concept of environmental efficiency has been extended to EE [10]. The World Business Council for Sustainable Development (WBCSD) initially defines the concept of EE as "a management philosophy that encourages business to search for environmental improvements which yield parallel economic benefits" [11]. Besides, WBCSD also details seven key principles of EE, which are: reduction in the material intensity of goods or services, reduction in the energy intensity of goods or services, reduction in the dispersion of toxic materials, improved recyclability of materials, maximum use of renewable resources, greater durability of products, production materials and equipment, increased service intensity of goods and services [11, 12].

Yu et al. discussed that EE is the main strategy for promoting sustainability through living within global resource carrying capacity [13]. EE is also recognized as a significant tool to evaluate environmental and economic challenges at the same time [14]. Specifically, it indicates that a firm operates in a good financial performance with less environmental impact or a high quality product with added value [15].

Mickwitz et al. argued that eco-efficiency could be viewed from many perspectives, such as the macro-economic (national economy), the meso-economic (region) and the micro-economic (company) levels [16]. In addition to the micro-economic level, EE has also been applied in corporate level, process level, and product level [17, 18]. EE is an essential component of corporate social performance. It also acts as forward-looking measures of firm financial performance for both researchers and practitioners [19]. Mickwitz et al. illustrated that EE is capable of reducing the environmental impact and natural resources, as well as maintaining or increasing the value of the output [16]. Thus, improving EE requires producing more desirable outputs (GDP), while reducing the consumption of resources and adverse ecological impacts [20].

Currently, EE is becoming an increasingly organizational performance measurement [21]. It is widely accepted as a means for both increasing economic value and reducing environmental affects [22]. It is also defined as the ratio of resource inputs ad waste outputs to final product [23]. It is considered an instrument for sustainability analysis, showing the empirical economic relationship between environmental cost or value and environmental input [16]. It is worth to mention that an exact definition of EE does not exist [24]. In this research, authors selected Sorvari et al.'s concept to define EE which is "to create more value with fewer resources and less negative impact" [25].

\subsection{Industrial symbiosis}

IS has been positioned within the IE field as a concept engaging "traditionally separate entities in a collective approach to competitive advantage involving physical exchange of materials, energy, water" [26]. The concept of IS was inspired by the observation of the Kalundborg network, in Denmark, in which exchanges of waste, by-products, and energy occur among closely situated companies over a period of more than 20 years [27, 28].

IS is seen as a means to progress towards a more eco-efficient industrial system [29]. Considering the system as a whole, the overall environmental performance would be higher than the performance at each individual the factory level [27]. At company level, IS brings additional opportunities to increase revenues through by-products sales or cost savings [30]. Moreover, IS 
This is a pre-copyedited version of a contribution published in Sustainable Design and Manufacturing 2017. KESSDM 2017. Smart Innovation, Systems and Technologies, Campana G., Howlett R., Setchi R., Cimatti B. (eds), published by Springer, Cham. The definitive authenticated version is available online via https://doi.org/10.1007/978-3-319-57078-5_57

based business strategies are currently enabling new business models that create value from waste and additionally allows to repurpose for society and environment at multi-organizational level [31]. Thus, providing a broader set of benefits, other than economic value, and for a broader range of stakeholders.

The key activities for IS applications are the recovery, reuse and recycle of waste (materials, water, or energy) from one facility as alternative input in a neighbouring facility [32]. Therefore, the final quantity of waste being disposed can be significantly reduced or even eliminated. Whereas there is a reduction of waste disposed, there are some additional benefits for the companies receiving the waste. Waste and byproducts can replace raw materials and fossil fuels in industrial processes [9], reducing supply costs for receiving companies.

In the present work, the definition given by Chertow in 2000 [26] and reported at the very beginning of this section has been taken as a reference.

\section{Conceptual framework}

Based on literature and definitions introduced in previous sections, authors identified three main aspects linking the concepts of EE and IS, which are 'Actions', 'Stakeholders' and 'Value'. These three aspects are present in most of the definitions identified and have therefore been used to drive the analysis of the interior relationship among EE and IS. IE has been considered as the leading concept for both EE and IS, and a comparative analysis of these drivers for IE and EE and IE and IS has been carried on.

"Actions" are all of the activities carried on by practitioners to either improving the performance of existing technologies, or creating new technologies [33]. At the firm level, IE is then analogous to EE [2]. In other words, the target of IE and EE is the same, i.e. to increase the value of the product while reducing the environmental impact through recycling, reusing and reducing. Specifically, examining definitions in the Oxford Dictionary, the action of recycling is "to convert (waste) into reusable material", reusing is defined as "the action of using something again", while reducing is "to make something become smaller or less in size, amount, or degree" [34]. The Cambridge dictionary adds a definition to recycling, which is "to use something again for a different purpose" [35]. In EE literature, the action of reusing is to repeat the usage of production wastes; recycling is to reuse raw materials and correctly dispose the items that cannot be reused; reduce is to decrease materials and energy intensity as well the dispersion of toxic substances $[11,12,36]$. In IS literature, reuse and recycle are the most important actions to reduce negative impacts such as the usage of oil, emissions of carbon dioxide and the quantities of waste disposal [37]. For instance, a recycling action for an industry might be to use waste products as an alternative energy source. This approach helps to relieve the community need to process this waste and also helps to limit CO2 emissions [38].

"Stakeholder" indicates all the individuals or groups that affect or are affected by the corporate actions [39]. For instance, companies, industries, regulators, interest groups, consumers, households and local communities, regions or countries [40, 41]. In IE, EE and IS, the configuration of the industrial system is created by many different actors or agents under a variety of coordination mechanisms such as organizations, markets, policy, and regulation. It's a context-based field of research and the solutions are strongly determined by contextual factors, where the detailed advantages to each party are not necessarily well understood [41, 42, 43]. In practical, there is no general differentiation among stakeholders involved in EE and IS, as it highly depends on the specific case and context.

"Value" is intended as an extensive set of benefits for different stakeholders. It entails different meanings from different stakeholders' point of view, which should be as aligned as possible to enable the realization of EE and IS implementation possibilities. In the sustainability perspective, value includes monetary profit, social and environmental aspects $[44,45]$. In this research, value has been considered in following perspectives: in IE, practitioners increase resources' value by closing resource loops; in EE, practitioners increase the value of the product from the customers' perspective; in IS, practitioners increase the value of waste and byproducts, as well as resources' value by creating mutually beneficial transactions. 
Considering what above concluded, it is possible to say that actions usually undertaken in EE and IS are very similar, with the only exception of "reduce". Whereas, IE and EE characterized by all three types of actions, which are "reduce", "reuse" and "recycle". Therefore, "Action" is not suitable to be selected as the main driver in a conceptual framework. 'Stakeholders' is a highly context-related driver. It depends on the specific situation and the definition relies on multi-party, which is why it will also not be considered as main driver in the conceptual framework. 'Value' is the only aspect that links the concepts of IE, EE and IS by the resources, customers and waste perspective. Therefore, authors decided to use 'Value' as the main driver and to use 'Actions' as subsidiary feature to build the conceptual framework. Figure 1 represents a synthesis of the conceptual framework proposed by the authors.

In this framework, as previously discussed, IE is selected as the leading concept, as it includes all actions, stakeholders and value associated with both EE and IS. IE is also usually referred to a higher level compared to EE and IS, i.e. regional or global level rather than intra-firm (which is the level used for EE) or both intra-firm and inter-firm (as exchanges are realized between processes, IS can occur between two different processes in a single firm or between different firms [41]). Based on the leading concept, the framework then makes a comparison between EE and IS in terms of actions and value generation. The framework clarifies the different actions undertaken in EE and IS, and also value management alternatives, that mainly differ in waste management strategies. Considering EE in production processes, the main aim of waste management is to produce less waste. The quantity of waste is decreased and the value is almost the same. In contrast, through IS implementation; the 'waste' would become by-product. This means that the value of the waste is increased and the quantity of the waste does not necessarily have to decrease in order to reduce negative impact and increase value.

The next section describes four cases of EE and IS basing on main concepts presented in the framework. It is worth to mention that for sake of brevity, authors will only describe four cases; deeper analysis will be conducted in further researches.

\section{Industrial cases}

\subsection{Eco-efficiency cases}

\subsubsection{Eco-efficiency case 1}

Ozturk et al. carried out a study aimed at reducing the environmental impact of a cotton/polyester fabric finishing-dyeing process in a textile mill located in Denizli, Turkey [46]. The mill is a mid-sized outsourcer dye house with two production lines, bleaching 2412 tons/year and dyeing 6682 tons/year. Main resources consumed by the plant are water, thermal energy and electricity. Water demand is provided from groundwater sources and mainly used in facility cleanings and finishing/dyeing processes; wastewater recovery and reuse techniques had never been implemented in the mill [46]. Thermal energy consumption, provided by coal and gas, is mainly consumed by steam and hot-oil boiler systems, while electricity is supplied from electricity grid and used for electric engines, lightings and other devices. Chemical usage is intensive at almost every stage of production processes. After an initial assessment, 92 different improvement actions were identified on the basis of Best Available Techniques defined by the European Commission (2003), then reduced to 22 after a feasibility study and prioritization process. In particular, systems to reuse/recovery washing wastewater and dye bath were introduced, as well as practices regarding the insulation of hot surfaces (tank, pipe, etc.), the optimization of boiler units, the heat recovery from separated hot wastewater and from flue gas and stenters. In addition, chemical consumption was reduced by removing iron from fabric surfaces before scouring process and by recovering caustic from mercerization process wastewater by membrane techniques and chemical substitution. As a result of the implementation of these improvement actions, a consistent reduction in the consumption of resources as well as in the production costs was achieved. The environmental impact was sensitively lowered by the chemical substitution in particular. 
This is a pre-copyedited version of a contribution published in Sustainable Design and Manufacturing 2017. KESSDM 2017. Smart Innovation, Systems and Technologies, Campana G., Howlett R., Setchi R., Cimatti B. (eds), published by Springer, Cham. The definitive authenticated version is available online via https://doi.org/10.1007/978-3-319-57078-5_57

\subsubsection{Eco-efficiency case 2}

A modern beef and lamb processing plant based in Northern Ireland can slaughter and process 1800 cattle and 4000 lambs per week, supplying meat products to major supermarket chains such Tesco, M\&S, Dunnes, Centra and Musgrave Supervalu. The company is highly committed to reduce its environmental impact and the amount of waste sent to landfill. The eco-efficiency actions implemented along these lines are the reduction of resources required for the process, reuse and recycle of wastes. In particular, their focus over the last years has been to improve the waste management and handling practices. In fact, the company was already recycling its cardboard and wood packaging waste, but had never created a system to segregate and recycle plastic packaging waste and cans. With the help of a consulting company and of a recycling company, the processing plant was able to start recycling 27 tons of plastic packaging and cans, saving up to $£ 5,700$ and reducing its carbon dioxide emission of about 280 tons [47]. This, consequently, lowered significantly manufacturing costs in the plant.

\subsection{Industrial symbiosis cases}

\subsubsection{Industrial symbiosis case 1}

A fruit juice concentrate producer in Iskenderen Bay, Turkey, generated 12,000 tons of fruit pulp waste each year as a by-product of its process and wanted to find a way to reuse the material rather than sending it to costly landfill. A team of researchers from the Faculty of Agriculture at Cukurova University, financed by the Turkish government, tested out potential ways to treat the pulp, making it suitable for reuse. In addition, a mining company, which wanted to find an outlet for its waste heat from lime production, was contacted as a potential partner. Researchers at the University carried out tests to dry the fruit pulp waste using the waste heat from the lime production process, successfully transforming the material into animal feed. The nutrient composition and energy value analysis proved that the quality of the animal feed end product was high, which was critical to the full commercialisation of the scheme. Implementing this three-way synergy redirected 115 tons of petroleum coke waste heat, reduced carbon dioxide emissions by 3,500 tons, reused 12,000 tons of waste pulp each year and produced 1400 tons of animal feed for reselling [48].

\subsubsection{Industrial symbiosis case 2}

A Scottish global manufacturer of alcoholic drinks receives the aromatics for its gin in hessian sacks, which were going to landfill after being emptied. The company was committed to finding a more sustainable alternative to landfill. A new business start-up based in Fife uses the staves from old whisky barrels to make firewood. The start-up was buying hessian sacks to package the firewood it was selling. The quality of hessian sacks landfilled by the drinks manufacturer was assessed and they were found clean and durable enough to be ideal to be used as firewood packaging. The sacks were declared as waste on the Pollution prevention and control license, so the drinks manufacturer was not immediately able to divert the sacks, but had to seek the help of a consultancy company, who started a dialogue with Scottish Environment Protection Agency. Eventually, it was possible to re-categorize the sacks from a waste to a by-product. This synergy has saved the start-up over $£ 20,000$ in packaging costs, which has helped them considerably as a newly funded company. The drinks manufacturer is also seeing cost benefits, as they no longer have to pay to dispose the sacks to landfill [47]. 
This is a pre-copyedited version of a contribution published in Sustainable Design and Manufacturing 2017. KESSDM 2017. Smart Innovation, Systems and Technologies, Campana G., Howlett R., Setchi R., Cimatti B. (eds), published by Springer, Cham. The definitive authenticated version is available online via https://doi.org/10.1007/978-3-319-57078-5_57

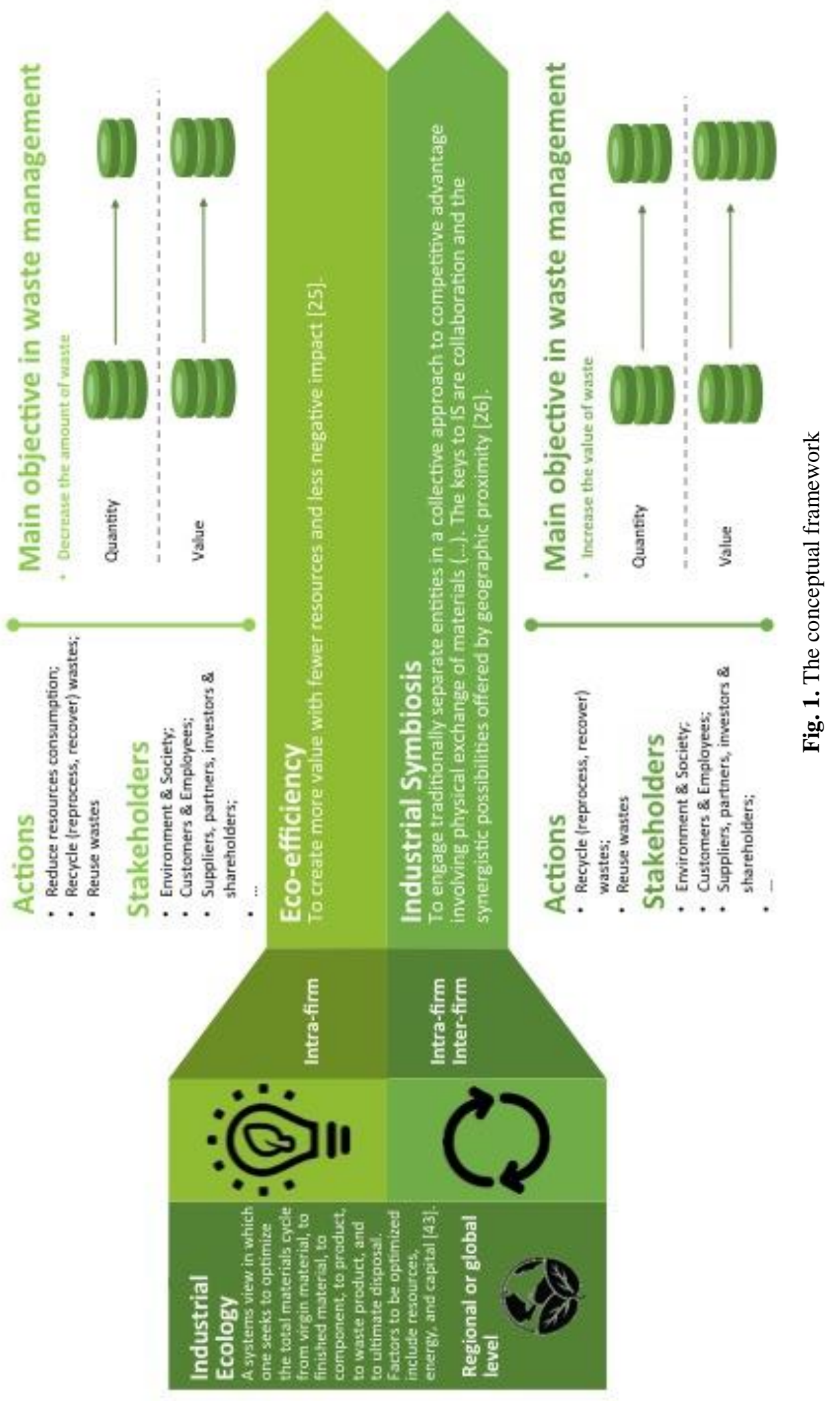


This is a pre-copyedited version of a contribution published in Sustainable Design and Manufacturing 2017. KESSDM 2017. Smart Innovation, Systems and Technologies, Campana G., Howlett R., Setchi R., Cimatti B. (eds), published by Springer, Cham. The definitive authenticated version is available online via https://doi.org/10.1007/978-3-319-57078-5_57

\subsection{Discussion about the cases}

The following Table 1 synthesizes key concepts of previously illustrated industrial cases. Actions vary slightly among the four cases, while stakeholders involved are different in all of them. In EE cases the quantity of waste is reduced and value is created for the company (and subsequently for the customer, as it will potentially lead to lower selling price), while in IS cases the waste is revaluated by giving it further use and, therefore, value is created for all the companies participating in the exchange.

Table 1. Cases analysis

\begin{tabular}{|c|c|c|c|c|}
\hline Case & Actions & Stakeholders & $\begin{array}{c}\text { Changes in waste } \\
\text { quantity and } \\
\text { value }\end{array}$ & Results \\
\hline $\begin{array}{c}\text { Case } 1 \\
\text { EE }\end{array}$ & $\begin{array}{l}\text { Reduce, } \\
\text { Reuse, } \\
\text { Recover }\end{array}$ & $\begin{array}{l}\text { Firm, landfills, } \\
\text { chemical } \\
\text { providers, energy } \\
\text { providers } \\
\text { customers, } \\
\text { technology } \\
\text { providers, } \\
\text { consultants, } \\
\text { customers, } \\
\text { environment, } \\
\text { operators, } \\
\text { population }\end{array}$ & $\begin{array}{l}\text { The quantity of } \\
\text { waste has been } \\
\text { drastically } \\
\text { reduced by } \\
\text { reducing resource } \\
\text { consumption }\end{array}$ & $\begin{array}{l}\text { Reduced costs, } \\
\text { reduced resources } \\
\text { consumption, } \\
\text { reduced } \\
\text { environmental } \\
\text { impact, value } \\
\text { created for the } \\
\text { company }\end{array}$ \\
\hline $\begin{array}{c}\text { Case } 2 \\
\text { EE }\end{array}$ & Recycle & $\begin{array}{l}\text { Firm, landfill, } \\
\text { consultants, } \\
\text { customers (B2C), } \\
\text { customers (B2B), } \\
\text { environment, } \\
\text { recycling } \\
\text { company, } \\
\text { population }\end{array}$ & $\begin{array}{l}\text { The quantity of } \\
\text { waste has been } \\
\text { drastically } \\
\text { reduced by paying } \\
\text { a recycler }\end{array}$ & $\begin{array}{l}\text { Reduced costs, } \\
\text { reduced } \\
\text { environmental } \\
\text { impact, value } \\
\text { created for the } \\
\text { company }\end{array}$ \\
\hline Case 1 IS & $\begin{array}{l}\text { Recycle } \\
\text { (impleme } \\
\text { nt } \\
\text { exchange } \\
\text { s) }\end{array}$ & $\begin{array}{l}\text { Government, } \\
\text { university, } 3 \text { firms } \\
\text { participating in } \\
\text { the exchange, } \\
\text { population, } \\
\text { operators, } \\
\text { technology } \\
\text { providers, } \\
\text { customers, } \\
\text { consultants, } \\
\text { landfill }\end{array}$ & $\begin{array}{l}\text { The value of } \\
\text { waste has been } \\
\text { increased }\end{array}$ & $\begin{array}{l}\text { Increased revenues, } \\
\text { reduced resources } \\
\text { consumption, } \\
\text { reduced } \\
\text { environmental } \\
\text { impact, value } \\
\text { created for three } \\
\text { companies }\end{array}$ \\
\hline Case 2 IS & $\begin{array}{l}\text { Recycle } \\
\text { (impleme } \\
\text { nt } \\
\text { exchange } \\
\text { s) }\end{array}$ & $\begin{array}{l}2 \text { firms } \\
\text { participating in } \\
\text { the exchange, } \\
\text { consultants, } \\
\text { government, } \\
\text { customers, sacks } \\
\text { providers, landfill, } \\
\text { population }\end{array}$ & $\begin{array}{l}\text { The value of } \\
\text { waste has been } \\
\text { increased }\end{array}$ & $\begin{array}{l}\text { Increased revenues, } \\
\text { reduced costs, } \\
\text { reduced resourced } \\
\text { consumption, } \\
\text { reduced } \\
\text { environmental } \\
\text { impact, value } \\
\text { created for two } \\
\text { companies }\end{array}$ \\
\hline
\end{tabular}


This is a pre-copyedited version of a contribution published in Sustainable Design and Manufacturing 2017. KESSDM 2017. Smart Innovation, Systems and Technologies, Campana G., Howlett R., Setchi R., Cimatti B. (eds), published by Springer, Cham. The definitive authenticated version is available online via https://doi.org/10.1007/978-3-319-57078-5_57

\section{Concluding remarks}

Based on the leading concept of IE, this research conducts a higher-level comparison between EE and IS. In theoretical, authors identify a conceptual framework and generalized the relationship of EE and IS. Specifically, EE is focus on the intra-firm while the processes of IS works on both intra and inter level of a firm. In the value perspective, EE is to reduce the amount of waste, which would reduce the cost of waste disposal. In contrast, IS is to increase the value of the waste, which increase the profit to the firm.

Case analysis reflects a recurring barrier to IS: pioneer companies that find a higher value solution for their waste (normally non-hazardous but categorized as waste by legislation) frequently struggle with current regulations and standards. Regulation can be in fact a key success factor if well managed but is often rather an obstacle for companies starting a symbiotic exchange [49]. In addition, case analysis suggested that IS implementation often requires the involvement of a third-party or consultant in order to be effective. This is not usually true as well for EE cases. Finally, it is often verified that IS exchanges do not happen because companies keep considering waste only as waste and not as valuable product, while in IS waste ceases to be waste, as "a waste product might no longer be waste when it is marketable as a useful and environmentally safe product" [31].

It is worth to mention that there is not one way to reduce environmental impact and increase economic value applicable universally. Tools and methods are needed to support the analysis of the most adequate strategy in each case; thus, prior to implementation plans, practitioners should have a comparison with other optimal mechanisms to work out the most effective solution in their case [41].

Further research will firstly address the generalizability of the framework. This will be conducted by analyzing a more extensive set of case studies on EE and IS applications. Additionally, this research will address an analysis of the capabilities for EE and IS to identify the possible synergies between them. This stage will actively involve manufacturing companies into the research activities, thus, a participatory research approach will be taken. Finally, this research will focus on the development of tools and / or methods to support companies willing to apply more effectively both EE and IS into their operations. These research results will provide them with guidelines to understand how IE can be implemented at firm level and to have a better performance on the implementation of EE and IS.

Acknowledgements This work was supported by the European Union's Horizon 2020 research and innovation program (grant no. 680570) and the EPSRC Centre for Innovative Manufacturing in Industrial Sustainability (grant no. EP/I033351/1).

\section{References}

1. Schaltegger S, Wagner M., Sustainable entrepreneurship and sustainability innovation:categories and interactions. Business Strategy and the Environment 20(4): 222237 (2011)

2. Lifset, R. and T. E. Graedel., "Industrial Ecology: Goals and Definitions." In Handbook for Industrial Ecology, edited by R. U. Ayres and L. Ayres (2001)

3. Joseph Huber, Towards industrial ecology: sustainable development as a concept of ecological modernization, Journal of Environmental Policy \& Planning, 2:4, 269-285 (2000)

4. Van Berkel, R., The Role of Eco-Efficiency in Industrial Ecology, Proceedings of the III International Conference on Industrial Ecology for a Sustainable Future, Stockholm, 12-15 June 2005 (2005) 
This is a pre-copyedited version of a contribution published in Sustainable Design and Manufacturing 2017. KESSDM 2017. Smart Innovation, Systems and Technologies, Campana G., Howlett R., Setchi R., Cimatti B. (eds), published by Springer, Cham. The definitive authenticated version is available online via https://doi.org/10.1007/978-3-319-57078-5_57

5. Boons F., Spekkink W., Mouzakitis Y., The dynamics of industrial symbiosis: a proposal for a conceptual framework based upon a comprehensive literature review. Journal of Cleaner Production, 19, 905-911 (2011)

6. Park and Behera, Methodological aspects of applying eco-efficiency indicators to industrial symbiosis networksJournal of Cleaner Production, 64 (2014), pp. 478-485 (2014)

7. Salmi O., Eco-efficiency and industrial symbiosis - a counterfactual analysis of a mining community. Journal of Cleaner Production, 15, 1696-1705 (2007)

8. Stindt, D. and Sahamie, R., Review of research on closed loop supply chain management in the process industry. Flexible Services and Manufacturing Journal, 26(1-2), 268-293 (2014)

9. Garetti M. and Taisch M., Sustainable manufacturing: trends and research challenges Prod. Plann. Control, 23 (2-3) (2012), pp. 83-104 (2012)

10. Schaltegger, S. and Sturm, A., Ökologische Rationalität (Ecologic Rationality). Unternehm 4, 273-290 (available only in German) (1990)

11. World Business Council for Sustainable Development (WBCSD). Eco-efficiency: Creating More Value with Less Impact, Geneva (2000)

12. WBCSD, Cross cutting themes: Eco-efficiency, World Business Council for Sustainable Development (1992)

13. Yu, Y., Chen, D., Zhu, B., \& Hu, S., Eco-efficiency trends in China, 1978-2010: Decoupling environmental pressure from economic growth. Ecological Indicators, 24, 177184 (2013)

14. Helena Carvalhoa, Kannan Govindanb, Modelling green and lean supply chains: An ecoefficiency perspective. Journal of Resources, Conservation and Recycling. (2017)

15. Ioannis E. Nikolaou*, Stefanos I. Matrakoukas, A framework to measure eco-efficiency performance of firms through EMAS reports. Journal of Sustainable Production and Consumption. (2016)

16. Mickwitz, P., Melanen, M., Rosenström, U., Seppälä, J., Regional eco-efficiency indicators: a participatory approach. Journal of Cleaner Production 14, 1603-1611 (2006)

17. Hahn, T., Figge, F., Liesen, A., Barkemeyer, R., Opportunity cost based analysis of corporate eco-efficiency: a methodology and its application to the CO2-effi- ciency of German companies. J. Environ. Manag. 91 (10), 1997-2007 (2010)

18. Kerr, W., Ryan, C., Eco-efficiency gains from remanufacturing: a case study of photocopier remanufacturing at Fuji Xerox Australia. J. Clean. Prod (2001)

19. Guenster, N., R. Bauer, J. Derwall, abd K. Koedijk., The economic value of corporate ecoefficiency. European Financial Management 17(4): 679-704 (2011)

20. Huang, J., Yang, X., Cheng, G., \& Wang, S., A comprehensive eco-efficiency model and dynamics of regional eco-efficiency in China. Journal of Cleaner Production, 67, 228-238 (2014)

21. Aanand Davéa, Konstantinos Salonitisa, Factory eco-efficiency modelling: framework application and analysis. 13th Global Conference on Sustainable Manufacturing Decoupling Growth from Resource Use. CIRP 40 (2016) 214 - 219. (2016)

22. Sun, Y.Y., \& Pratt, S., The Economic, Carbon Emission, and Water Impacts of Chinese Visitors to Taiwan: Eco-efficiency and Impact Evaluation. Journal of Travel Research, 53(6), 733-746 (2014)

23. Schmidheiny, S., Changing Course: a Global Business Perspective on Development and the Environment. Business Council for Sustainable Development, MIT Press, Cambridge, MA (1992)

24. Koskela, M., Measuring eco-efficiency in the Finnish forest industry using public data. Journal of Cleaner Production, 98, 316-327 (2014)

25. Sorvari, J., Antikainen, R., Kosola, M.-L., Hokkanen, P., Haavisto, T., Eco-efficiency in contaminated land management in Finland e barriers and development needs. J. Environ. Manag. 90, 1715e1727 (2009) 
This is a pre-copyedited version of a contribution published in Sustainable Design and Manufacturing 2017. KESSDM 2017. Smart Innovation, Systems and Technologies, Campana G., Howlett R., Setchi R., Cimatti B. (eds), published by Springer, Cham. The definitive authenticated version is available online via https://doi.org/10.1007/978-3-319-57078-5_57

26. Chertow, M. R., Industrial symbiosis: literature and taxonomy, Annual Review of Energy and the Environment, 25(1), 313-337 (2000)

27. Ehrenfeld, J. R., Gertler, N., Industrial ecology in practice: The evolution of interdependence at Kalundborg. J Ind Ecol 1(1), 67-79 (1997)

28. Jacobsen, N.B.: Industrial symbiosis in Kalundborg, Denmark: a quantitative assessment of economic and environmental aspects. Journal of Industrial Ecology. 10(1 - 2), 239-255 (2006)

29. Doménech, Teresa, Davies, Michael, The role of embeddedness in industrial symbiosis networks: phases in the evolution of industrial symbiosis networks. Bus. Strategy Environ. 20 (5), 281-296 (July 5) (2011)

30. Paquin R. L., Busch T., Tilleman S. G., Creating Economic and Environmental Value through Industrial Symbiosis. Long Range Planning, 48, 95-107 (2015)

31. Ruiz Puente, M.C., E. Romero Arozamena and S. Evans, 'Industrial symbiosis opportunities for small and medium sized enterprises: preliminary study in the Besaya region (Cantabria, Northern Spain)', Journal of Cleaner Production, 87, 356-374 (2015)

32. Van Berkel, R., Comparability of industrial symbioses, Journal of Industrial Ecology, 13(4), 483-486 (2009)

33. Eco-efficiency action project, Methods, Models, \& Analytics for Sustainable Operations Management. http://eco-efficiency-action-project.com (2014)

34. Oxford dictionary. https://en.oxforddictionaries.com. Last accessed Nov. 2016.

35. Cambridge dictionary http://dictionary.cambridge.org/dictionary/english/recycling Last accessed Nov 2016.

36. C. R. C. Mohanty, Reduce, Reuse and Recycle (the 3Rs) and Resource Efficiency as the basis for Sustainable Waste Management, Synergizing Resource Efficiency with Informal Sector towards Sustainable Waste Management (2011)

37. Jefferson Hopewell et al, Plastics recycling: challenges and opportunities. Philosophical transactions of the royal society B. 10.1098/rstb.2008.0311 (2009)

38. Industrial ecology and recycling, Sustainability report. http://www.lafarge.com/05182012publication_sustainable_development-Sustainable_report_2011-industrial-ecology-uk.pdf. Last accessed Nov. 2016 (2011)

39. R. Edward Freeman, Stakeholder theory of the modern cooperation, General Issues in Business Ethics (2012)

40. Posch, A.: Industrial recycling networks as starting points for broader sustainability-oriented istepicooperation? J. Ind. Ecol. 14(2), 242-257 (2010)

41. Holgado, M.,. Morgan, D., Evans, S., Exploring the Scope of Industrial Symbiosis: Implications for Practitioners, Sustainable Design Manufacturing International conference, Greece (2016).

42. Dijkema, G. P. J., \& Basson, L., Complexity and Industrial Ecology Foundations for a Transformation From Analysis to Action, (June), 157-164 (2007)

43. Chertow, M. R., Industrial symbiosis: Literature and Taxonomy. Annual Review of Energy and the Environment. Vol. 25: 313-337 (2000)

44. Rana, P., Short, S., Evans, S., D2.5 - Lessons Learned Report, Documenting the Impact from Use of the Tools \& Methods and Areas for Improvement. (2013)

45. State-of-practice in business modelling and value-networks, emphasising potential future models that could deliver sustainable value.

http://www.sustainvalue.eu/publications/D2_1_Final_Rev1_0_web.pdf. Last accessed Nov. 2016.

46. Ozturk, E., Koseoglu, H., Karaboyaci, M., Yigit, N. O., Yetis, U., Kitis, M.: Sustainable textile production: cleaner production assessment/eco-efficiency analysis study in a textile mill. J. Cle. Prod. 138, 248-263 (2016)

47. Invest Northern Ireland: Industrial Symbiosis - Improving productivity through efficient resource management - Guide for Businesses in Northern Ireland. 
This is a pre-copyedited version of a contribution published in Sustainable Design and Manufacturing 2017. KES-

SDM 2017. Smart Innovation, Systems and Technologies, Campana G., Howlett R., Setchi R., Cimatti B. (eds), published by Springer, Cham. The definitive authenticated version is available online via https://doi.org/10.1007/978-3-319-57078-5_57

https://secure.investni.com/static/library/invest-ni/documents/industrial-symbiosis-guide-forbusinesses-in-northern-ireland.pdf, last accessed Nov. 2016.

48. Iskenderun Bay Industrial Symbiosis. http://www.internationalsynergies.com/projects/iskenderun-bay-industrial-symbiosis/ Last accessed Nov. 2016.

49. Costa I., Ferrao P., A case study of Industrial symbiosis development using a middle-out approach. Journal of Cleaner Production. 18(2010) 984-992 (2010) 